EGU21-8805, updated on 30 Apr 2021

https://doi.org/10.5194/egusphere-egu21-8805

EGU General Assembly 2021

(c) Author(s) 2021. This work is distributed under

the Creative Commons Attribution 4.0 License.

\title{
Wildfire extreme events: Large-scale developments in fire activity of New South Wales, Australia
}

\author{
Michael Nolde ${ }^{1}$, Norman Mueller ${ }^{2}$, Günter Strunz ${ }^{1}$, Florian Fichtner ${ }^{1}$, Simon Plank ${ }^{1}$, and Torsten \\ Riedlinger ${ }^{1}$ \\ ${ }^{1}$ German Aerospace Center (DLR), Geo-Risks and Civil Security, Wessling, Germany (michael.nolde@dlr.de) \\ ${ }^{2}$ Geoscience Australia / Australian Government, Canberra ACT (Norman.Mueller@ga.gov.au)
}

Disastrous wildfires have occurred in many parts of the world during the last two years (2019 and 2020), most notably in South America, Australia, the United States, and regions north of the polar circle. Such extreme wildfire events pose a pervasive threat to human lives and property and have thus been widely recognized in the global media. This study focusses on large-scale developments in fire activity. It investigates the occurrence of burnt areas regarding several relevant parameters, namely fire extent, fire severity and fire seasonality. The entirety of those parameters allows an extensive insight regarding large-scale, long-term fire activity trends.

The burnt area derivation process, which is fully automated, is described in the literature (see reference below). The analysis is based on an extensive set of satellite data, specifically 9,612 granules of the MODIS MOD09/MYD09 product in conjunction with 3,503 tiles of the OLCI (Ocean and Land Colour Instrument) instrument onboard Sentinel-3.

The study design consists of two parts:

Firstly, the long-term temporal variability in fire activity, covering the time span from 2000 until 2020 , is analyzed for the study region of New South Wales, Australia.

Secondly, the large-scale spatial variability is investigated by comparing the New South Wales extreme events in 2019/2020 with events of comparable magnitude in California, US and the Siberian taiga.

The study shows that New South Wales features an upward trend regarding the extent of yearly affected area, as well as a shift towards a prolongated end of the fire season towards the Autumn months. It also shows the exceptionality of the Australian wildfire activity in comparison with other geographical regions.

Reference:

Nolde, Michael; Plank, Simon; Riedlinger, Torsten. "An Adaptive and Extensible System for Satellite- 
Based, Large Scale Burnt Area Monitoring in Near-Real Time." Remote Sensing 12.13 (2020): 2162. 